\title{
Introduction: The Philosophy of Expertise-What is Expertise?
}

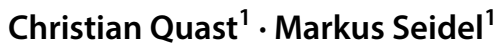

Published online: 6 December 2017

๑) Springer Science+Business Media B.V., part of Springer Nature 2017

\section{The Philosophy of Expertise}

In modern societies it is virtually impossible to abstain from trust in expert advice: be it in everyday contexts such as asking the train attendant about the arrival time at the next station or in scientific contexts, in which research projects of so-called 'Big Science' demand the cooperation of many scientists. As a matter of fact, the omnipresent phenomenon of expertise has been in disciplinary focus especially by sociologists (see e.g. Collins and Evans 2007 and; Collins 2014) and psychologists (see e.g. Ericsson et al. 2006). However, due to the development of social epistemology and integrated research in the border area of sociology and philosophy of science the phenomenon of expertise also gained more and more attention by philosophers. Seminal in this respect were the paper of Hardwig (1985) and Goldman (2001) which not only initiated the modern philosophical debate, but also raised a couple of hitherto unsettled questions such as:

- What is expertise?

- What is the function of expertise or what are its desiderata respectively?

- What kinds of expertise are there?

- Is there a reasonable (cognitive) threshold for being an expert?

- What is expert knowledge and how to represent it?

- How can a layperson identify experts and rationally distinguish between experts and frauds?

- What is metaexpertise, who possesses it and which are the criteria for it?

- Can there be rational disagreement between experts and, if so, how can we account for it?

Christian Quast

christian.quast@wwu.de

Markus Seidel

markus.seidel@wwu.de

1 University of Muenster, Muenster, Germany
- Do we have any reasonable alternative to expertise or is our trust in experts plainly unavoidable?

- Individuals or collectives: what is a proper subject of expertise?

However, despite the pervasive use of experts not only in scientific practices and the increasing interest in the conceptual and epistemological issues concerning expertise, the philosophical discussion about experts and expertise must be said to be still in fledgling stages. Indeed, the study of various forms of expertise did not reveal a definite answer to any of the above questions. Moreover, perspectives on potential answers to this question differ across disciplines. Most notably, philosophy, psychology and the social sciences provide diverse angles from which to explore the nature, value and function of experts. Correspondingly, there is an urgent need to clarify the most fundamental questions surrounding the conceptual nature of expertise.

The present special issue aims at filling this gap by bringing together contributions of leading scholars on the topic of expertise from different areas of philosophy and with different disciplinary backgrounds so that the nature, value and function of expertise can be explored from different points of view. The main focus stays on the conceptual and social epistemological issues concerning the notion of expertise. Thereby, the issue aims at pursuing already existing threads in applied social epistemology as well as providing a prospective reference point for a blossoming debate about the conceptual clarification of the issue of expertise.

\section{The Papers of this Issue}

The papers of this special issue can be basically divided into two main groups.

The first group of papers mainly addresses conceptual questions concerning the nature of expertise by pursuing roughly classical conceptual analysis and explication.

Alvin Goldman introduces several approaches to define intellectual expertise none of which he ultimately subscribes 
to as a general account. This, however, does not lead him to debunk the pertaining notion. Instead, he conceives of expertise as a variable and fluid concept such that different criteria for it can be used in different contexts.

In contrast to this, Christian Quast offers a general account of expertise by conducting a practical explication in the spirit of Edward Craig's Knowledge and the state of nature. Thereby, he argues that the nature and value of expertise is best understood by a certain service-function, i.e. in the light of its social role. In this way, his explication interprets expertise as a social kind which not only requires contextually sufficient competences, but also a special responsibility on behalf of the expert. This is why he considers expertise to feature a descriptive as well as a deontic dimension.

Like Quast, Oliver Scholz methodologically does not opt for a conceptual analysis of the notion of expertise. Instead of aiming to provide necessary and sufficient conditions, he proposes to focus on the various symptoms of expertise. Amongst them, he stresses the importance of understanding and begins to develop an account of it.

Jamie Watson criticizes veritistic attempts that characterize the notion of expertise via the notion of truth. In contrast, he offers what he calls an epistemic facility account of intellectual expertise. Roughly, according to this account, experts possess the understanding as well as the ability to demonstrate such understanding in their subject area of expertise.

The second group of papers aims at answering the conceptual questions by focusing on specific case studies as well as historical roots of the debate.

In a case study, the philosopher Martin Carrier and the sociologist Wolfgang Krohn analyze empirical data concerning the German expert commission on radiation protection.
They show that the commission does not just apply existing scientific knowledge to provide policy advice, but actively engages in model building. In their analysis, the authors then show how epistemic as well as non-epistemic considerations interact in the commission's activities.

Harry Collins introduces a program he calls 'Studies of Expertise and Experience' (SEE) as a contrast to many philosophical approaches. According to this program, expertise is acquired by socialization within expert communities, but once acquired represents a non-relational property. Therefore, being an expert is independent of whether only a small or large group of people are highly competent in the domain at issue.

Jörg Hardy and Margarita Kaiser inspect Plato's dialogues with respect to Socrates' remarks on expertise. According to their interpretation, good life must be understood in terms of epistemic autonomy. Therefore, for Socrates, it is crucial to trust your own reason and not to let any expert tell you about your own happiness.

\section{References}

Collins H (2014) Are we all scientific experts now? Polity Press, Cambridge

Collins H, Evans R (2007) Rethinking expertise. University of Chicago Press, Chicago

Craig E (1990) Knowledge and the State of Nature: an Essay in Conceptual Synthesis. Clarendon Press, Oxford

Ericsson KA, Charness N, Feltovich PJ, Hoffman RR (eds) (2006) The Cambridge handbook of expertise and expert performance. Cambridge University Press, Cambridge

Goldman AI (2001) Experts: which ones should you trust? Philos Phenomenol Res 63/1:85-110

Hardwig J (1985) Epistemic dependence. J Philos 82/7:335-349 